\title{
OS IDIOCULTUREMAS EM CAPITÃES DA AREIA (1937), DE JORGE AMADO
}

\author{
IDEOCULTUREMES IN JORGE AMADO'S \\ OF THE SANDS (1937)
}

\author{
Vicente de Paula da Silva Martins* \\ Universidade Estadual Vale do Acaraú, Sobral, CE, Brasil \\ Márton Tamás Gémes** \\ Universidade Estadual Vale do Acaraú, Sobral, CE, Brasil
}

\begin{abstract}
Resumo: Neste trabalho, apresentamos um estudo dos culturemas relacionados à cultura linguística (denominados, aqui, de idioculturemas) que marcam estilisticamente o discurso literário do escritor baiano Jorge Amado. Objetivamos analisar as escolhas lexicais do autor no romance Capitães da Areia (1937), com a intenção de elaborar, futuramente, um glossário a ser anexado à referida obra, com fins de práticas de leitura literária na educacãa básica, no qual apresentamos os culturemas mais expressivos na referida obra do ponto de vista da estilistica léxica e suas definições conforme o Dicionário Houaiss (2009). Para o desenvolvimento do estudo, recorremos às teorias fraseológicas e linguísticas, considerando que a linguagem utilizada por Jorge Amado é um reflexo da interação entre sociedade, língua, literatura e cultura, sendo o discurso literário, por excelência, a instância discursiva que transfere para a produção romanesca do escritor o reflexo da sua influência cultural nos anos 30.
\end{abstract}

Palavras-chave: Léxico; Culturemas; Literatura Brasileira; Discurso Literário; Regionalismo linguístico.

Abstract: In this paper we present a study of culturemes related to linguistic culture (called here idioculturemes) that mark the literary discourse of Jorge Amado stylistically. We propose to analyse the lexical choices made by the author in Capitães da Areia (1937, Captains of the Sands), having the intention to later develop a glossary that could be attached to the novel, as a practical help towards reading in basic education. In this glossary we present the most expressive cultureme (cultural remarks) in this novel, from the perspective of lexical stylistics and their definitions as they are in Dicionário Houaiss (2009). We based our study on phraseological and linguistic theories, since the language used by Jorge Amado may be understood as a reflection of the interaction between society, language, literature and culture, and being that literary discourse the quintessential discursive instance and which transfers to the author's novelistic production his cultural influence in the 1930's.

Keywords: Lexis; Culturemes; Brazilian Literature; Literary Discourse; Linguistic Regionalism

* Doutor da Universidade Estadual Vale do Acaraú - UVA, Sobral, CE, Brasil; vicente.martins@uol.com.br

** Doutora da Universidade Estadual Vale do Acaraú - UVA, Sobral, CE, Brasil; mgemes@hotmail.com

http://dx.doi.org/10.11606/issn.2236-4242.v32i3p117-136

Todo conteúdo da Linha D'Água está sob Licença Creative Commons Attribution-NonCommercial 4.0 International License 
Linha D’Água (Online), São Paulo, v. 32, n. 3, p. 117-136, set.-dez. 2019

\section{Introdução}

O presente trabalho tem por objetivo mostrar alguns culturemas relacionados à cultura linguística de cunho regional presentes no romance Capitães de Areia, em sua edição de 1937. A narrativa literária é uma privilegiada fonte de extração de culturemas, unidades culturalmente motivadas (SANTIAGO, 2014), posto que nos possibilita o contato com tempos e espaços que não conhecemos ou simplesmente ignoramos. Daí o estudo dos culturemas tornar-se insumo importante para a elaboração das sequências didáticas por docentes, sobretudo os que atuam na educação básica ou os que ministram aulas de Português Brasileiro (PB) como L2. Não há dúvida, pois, do alcance didático-pedagógico da leitura literária na formação de novos leitores.

Em Capitães da Areia (1937), de Jorge Amado, o culturema causa fascínio em falantes ou leitores do Português Brasileiro (PB) e não menos em ouvintes ou leitores do PB como L2, que facilmente observam e contemplam as relações entre Língua e Cultura mais representativas da cidade de Salvador e das relações sociais descritas pelo romancista na década de 30, particularmente as presentes no âmbito das instituições culturais, universo social, cultural, material e de identidade línguocultural, marcadamente regionais, idiossincrásicas e com o jeito próprio baiano de ser.

O romance Capitães da Areia (AMADO, 1937) relata a experiência de vida marginalizada e a luta cotidiana por sobrevivência de um grupo de menores abandonados, tendo como principal cenário a Cidade Alta e a Cidade Baixa, em Salvador. Do ponto de vista da Estilística, trata-se de um romance regional com bastante riqueza de componentes morfológicos da estilística léxica, isto é, desde os primeiros capítulos, evidenciam-se aspectos expressivos de lexias simples (chibungo), composta (fura-greve) e complexa (bate o trinta e sete), ligados aos elementos semânticos e morfológicos da língua, os quais são ligados também, expressivamente, a aspectos sintáticos e contextuais, como, por exemplo, no contexto do culturema (andar ao léu): "Gostava de andar ao léu nas ruas da cidade, entrando nos jardins para fumar um cigarro sentado num banco, entrando nas igrejas para espiar a beleza do ouro velho, flanando pelas ruas calçadas de grandes pedras negras" (AMADO, 1937, p. 94).

MARTINS, V. P. S., GÉMES, M. T. Os idioculturemas em Capitães da Areia (1937), de Jorge Amado Todo conteúdo da Linha D'Água está sob Licença Creative Commons Attribution-NonCommercial 4.0 International License 
Dada a riqueza lexical do romance, foi possível extrairmos 634 culturemas nos sete âmbitos ou áreas estudadas (ecossistema, história, mitos e legados, organização social, instituições culturais, universo social, cultura material e identidade línguo-cultural). A rigor, todos os culturemas selecionados dizem muito do esforço de Jorge Amado de realmente estabelecer uma obra de cunho regional sem qualquer subserviência a um modelo regionalista ou escola literária dos anos 30 .

A obra de Jorge Amado se distingue de outros romances dos anos 30 por sua forte carga ideológica, com elementos fortes da língua e cultura, o equivale a dizer que há expressiva presença de um léxico culturalmente marcado, cuja linguagem regional está condicionada pela fala de seus usuários (crianças de rua, representantes das classes mais desprovidas de recursos) e inserta num contexto sócio-político da década de 30 também marcante, de modo a fazer frente às estratégias de controle colocadas em jogo pelo Estado Novo durante a Revolução de 30, estando à frente o político gaúcho Getúlio Vargas.

Com um número tão expressivo de referentes culturais, debruçamo-nos sobre os culturemas mais recorrentes em cada um dos âmbitos mencionados. Assim, no âmbito das Instituições Culturais, demos atenção aos tabuculturemas, isto é, os culturemas referentes à cultura religiosa, às crenças e aos tabus. Do Universo Social, selecionamos os antropoculturemas, isto é, os culturemas relacionados aos nomes próprios, pseudônimos, nomes de batismos e alcunhas, bem como os que denominamos de geoculturemas, culturemas relacionados à geografia cultural, com referência a populações, estados, munícipios, distritos, localidades, estrutura viária, ruas, países e toponímia. Esse inventário léxico-semântico revela muito da expressividade estilística da obra.

No âmbito da identidade línguo-cultural, foco de apresentação no presente estudo, extraímos exemplos de idioculturemas, basicamente os de cunho fraseológico (expressões idiomáticas e locuções diversas).

\section{Culturema, língua e cultura no discurso literário}

Os teóricos que embasaram nosso estudo são Pamies Bertrán (2008), Luque Nadal (2009) e Igareda (2011), quando tratamos dos princípios da culturologia, do 
conceito e da classificação de culturemas; e Corpas Pastor (1996), Martins (2013), entre outros, quando buscamos os pressupostos da Fraseologia Geral, mais especificamente, os idiomatismos decorrentes da cultura linguística no campo literário, a que denominamos neologicamente aqui de idioculturemas.

No âmbito dos aspectos linguísticos, este trabalho se justificou, desde logo, devido à escassez de estudos com foco nos culturemas na literatura brasileira, sendo predominante os estudos voltados para o campo de Tradução. Além disso, soma-se a necessidade de desenvolver pesquisas que envolvam a obra de Jorge Amado seguindo os aspectos correspondentes à língua e Estilística Léxica, uma vez que a maioria de estudos atuais está relacionada aos aspectos literários, deixando à margem os estudos do léxico.

Precisamos unir língua e literatura e estudar o discurso literário do ponto de vista linguístico (MOÇO, 2015; e CARDOSO, 2018). A língua portuguesa, o que inclui, evidentemente, o conjunto de suas literaturas europeia, africana e brasileira, é resultado de experiências coletivas, da memória cultural que se materializou antes do surgimento de nossa noção de nacionalidade e também dos passos que cada um de nós demos ao longo de mais de cinco séculos na construção de nossa brasilidade. Essas experiências deixaram e continuam deixando marcas na literatura, arte, folclore e música; em particular, as experiências línguo-culturais revelam muito do que verdadeiramente somos enquanto brasileiros, porque expõem nossas idiossincrasias, comportamentos, atitudes, linguagens, artes, ideologias e culturas.

Nessa perspectiva estritamente línguo-cultural, a cultura, entendida como etapa evolutiva de valores morais, intelectuais e espirituais de uma comunidade linguística, segue uma linha quase imperceptível com a linguagem literária, de modo que língua e cultura formam instrumentos inseparáveis (MIRANDA MÁRQUEZ, 2014). É a língua que se encarrega de criar elementos da cultura linguística capazes de expressar as formas particulares em que os falantes ou escritores percebem o mundo a sua volta. Um desses elementos são os chamados culturemas, objeto de nossa atenção neste estudo. Com isto, podemos afirmar que os culturemas criam e constroem limites para outras comunidades linguísticas ou para grupos divergentes dentro da mesma comunidade. Portanto, conhecimento e emprego de culturemas 
específicos demarcam aquilo que Elias e Scotson (2000) definem como outsider $\mathrm{x}$ insider, criando experiência de pertence e, finalmente, identidade.

Seguindo o instigante ponto de vista etimológico, o termo culturema, como unidade discreta da Culturologia (LUQUE NADAL, 2012) e com emprego semelhante a outras unidades linguísticas (fonema, morfema, semantema), vem de cultura, palavra originada do latim cultüra, ae e tem sentido de cuidar, tratar, venerar (no sentido físico e moral), acrescido do profícuo sufixo -ema. O elemento antepositivo cult-vem, por sua vez, do verbo latino colo, is, colüi, cultum, colère que, diz respeito ao ato de plantar e desenvolver atividades agrícolas. Por ampliação, mais tarde, desenvolveu-se o sentido "cultivar a mente".

Partimos do pressuposto de que os culturemas são referenciais culturais de determinada língua e geralmente expressos em unidades do léxico ou lexias de diversos níveis - complexas, compostas e simples, na terminologia de Pottier (1978) -, e que outras combinatórias fixas podem também revelar formas particulares ou especiais de o falante ver e representar a realidade ou o mundo (dimensão extralinguística).

A partir do texto literário, entendemos que são os culturemas que formam parte do patrimônio línguo-cultural, determinando os traços e a construção sociocultural do idiotismo da língua, com traços peculiares do espirito da nação e com reflexos, por força do relativismo linguístico, na comunicação, cultura e convenção social (MILANI, 2008; TANOS ROBEIN, 2013).

Ao certo, são os culturemas as unidades linguísticas, por excelência, responsáveis por fatores de idiomaticidade opaca por parte de falantes não nativos do $\mathrm{PB}$ quando estão diante de fraseologismos frequentes na língua-alvo com constituintes identificados como próprios do regionalismo literário ou linguístico. Por vezes, as corruptelas ou variações linguísticas chamam a atenção dos falantes não nativos porque, apesar de evocarem a fixação fraseológica das formas canônicas das fraseologias, têm forte apelo no dialetismo popular, nos termos de Zuluaga (1980), sem falar que essas formas variantes provocam uma metaforicidade alta (MARTINS, 2013), em benefício ou não da compreensão ou interpretação do leitor. Substancialmente, no campo literário, podemos afirmar, com segurança, que são os fraseologismos as unidades linguísticas que podem se tornar um obstáculo na compreensão leitora, sejam os leitores nativos ou não nativos de língua portuguesa. 
Linha D’Água (Online), São Paulo, v. 32, n. 3, p. 117-136, set.-dez. 2019

A definição de culturema adotada em nosso estudo aproxima-se do que postula Pamies Betrán (2008, p. 54), precursor nos estudos desse elemento associado à teoria fraseológica, que considera os culturemas como "símbolos culturalmente motivados", funcionando como alusões simbólicas. Essas referências culturais da língua geralmente são compostas por lexias compostas ou simples além de combinatórias fixas e correspondem a uma dimensão extralinguística, ou seja, são capazes de representar as particularidades de uma comunidade. Numa palavra, não podemos compreender bem uma obra como Capitães da Areia (AMADO, 1937) sem fazermos alusão ao Estado Novo, fase ditatorial da Era Vargas.

Os estudos brasileiros referentes aos culturemas, quando abordados dentro da área da Fraseologia, ainda são recentes e de pequeno número, para não dizermos escassos. A maior incidência de pesquisas sobre os culturemas no Brasil diz respeito, como dissemos anteriormente, ao campo da Tradução, no qual são também conhecidos como referências culturais. Nesses trabalhos, como os de Molina Martínez (2001), Giracca (2013) e Mattioli (2014), a temática culturológica tem sido tratada de maneira tangenciada e como forma de elucidar outros tópicos não diretamente relacionados às práticas de leitura literária. Em todo caso, vale ressaltar a relevância das pesquisas que buscam tratar as manifestações culturais nos elementos linguísticos.

Os culturemas podem estar associados a diversos setores da vida humana, como acontecimentos históricos, gastronomia, política, religião, geografia, arte, costumes e tantos outros. Além disso, os culturemas contribuem para a formação de imagens mentais tradicionais. Por exemplo, dizemos que é de cortar o coração algo que causa emoções relacionadas com a tristeza ou com a compaixão, ou seja, entendemos o coração como instrumento dos sentimentos, à guisa das civilizações antigas. E ao dizermos que alguém é duro de cabeça é o mesmo que dizer teimoso, obstinado, ou se dizemos sem cabeça é o mesmo que não temos condiçôes de pensar, de raciocinar sobre um determinado assunto no momento, sendo então a cabeça o símbolo da razão.

Podemos conceber os culturemas como signos ideológicos, uma vez que trazem a realidade concreta e abstrata do indivíduo e refletem a vivência de mundo, devendo ser compartilhados com outros de uma mesma cultura para que sejam compreendidos (OYARZABAL, 2013, p. 63)

MARTINS, V. P. S., GÉMES, M. T. Os idioculturemas em Capitães da Areia (1937), de Jorge Amado Todo conteúdo da Linha D'Água está sob Licença Creative Commons Attribution-NonCommercial 4.0 International License 
Para identificação dos culturemas em Capitães da Areia (AMADO, 1937), alguns aspectos linguísticos foram previamente levados em conta para definirmos o que poderia ou não ser considerado unidades linguisticamente motivadas.

Tomamos como ponto de partida os estudos de Luque Nadal (2009), que estabelece alguns critérios para reconhecer se um fato linguístico cumpre os requisitos necessários para noção de culturema. Um deles, por exemplo, é o que a autora chama de vitalidade, figuratividade e motivaçẫo, que diz respeito à usabilidade das expressões pelos falantes. Interessante exemplo de expressão idiomática marcada pelo anacronismo ou obsoletismo é dado por Cerqueira (2018) com a locução voltar à vaca-fria, com sentido equivalente ao de retomar uma questão interrompida ou o assunto principal, que caiu, segundo a autora, em total desuso na língua portuguesa; portanto, de baixa frequência ou usabilidade fraseológica. No entanto, a literatura marca e preserva justamente essas expressões idiomáticas obsoletas que, em consequência, se tornam talvez o maior desafio para o leitor contemporâneo, como podemos conferir na expressão acabar tutu, dado que é desconhecida pela maioria dos falantes hoje em dia.

Segundo Cerqueira (2018), outros culturemas, principalmente os oriundos de religiões e fatos históricos, tendem a ser mais duradouros na língua. A partir desse importante critério, entendemos que os culturemas precisam ter um sentido compartilhado pela comunidade (CASARES, 1969) em benefício da idiomaticidade (sentido metafórico) e da fixação (repetição), propriedades fraseológicas disponíveis para os falantes.

Tomando ainda como referência o estudo de Luque Nadal (2009), diríamos que o critério "produtividade fraseológica do culturema" (LUQUE NADAL, 2009, p.105) refere-se às variações fraseológicas que podem ser facilmente compreendidas. Voltando a Cerqueira (2018), que analisa a presença de culturemas em texto literário, são essas variações que indicam que os culturemas têm uma entidade mental própria. O culturema judas, por exemplo, refere-se ao antropônimo Judas Iscariotes, discípulo traidor de Jesus Cristo, alusão imprescindível para compreendermos as tradições medievais do queimar ou malhar o Judas, assim como o verbo judiar com sentido de causar sofrimento físico ou moral; atormentar, maltratar, acepção que resulta do mesmo modo da antiga tradição antissemita de origem europeia. 
Esses critérios acima assinalados serviram como base para identificação dos culturemas em Capitães da Areia (AMADO, 1937), que foram, posteriormente, recategorizados para fins didáticos, tendo como ponto de partida o modelo de Igareda (2011).

Surpreendentemente, encontramos dificuldade em separar os conceitos de Culturologia da Fraseologia na análise do texto literário. As dificuldades se dissiparam à medida que chegamos à conclusão de que as principais pesquisas culturológicas têm um fundo fraseológico (LUQUE NADAL, 2012), ou seja, a compreensão de expressões idiomáticas não se assenta predominantemente na configuração sintática, e sim, no sentido não composicional da expressão, ainda que a expressão seja semântica e pragmaticamente aceita para o sentido composicional (LEGROSKIL, 2012).

Evidentemente, a Fraseologia e a Culturologia podem ser estudadas a partir de aportes teóricos de outras áreas do conhecimento, como os das ciências sociais, em particular, os da antropologia cultural (a estratificação social, o ciclo de vida, a cultura imaterial, a arte e o folclore).

Este trabalho assume, todavia e, principalmente, os pressupostos de Corpas Pastor (1996, p. 20) para delimitação do campo de estudo, os quais consideram a Fraseologia como parte da Linguística que se encarrega do estudo das unidades fraseológicas, também chamadas de fraseologismos. Nesse sentido, entende-se que a Fraseologia estuda o léxico da língua não constituído de vocábulos soltos e independentes, mas sim de combinações fixas.

Essas combinações, também ditas lexias, são registradas por grande parte dos dicionários da língua portuguesa, como por exemplo, falar pelos cotovelos, geralmente encontrada dentro do verbete cotovelo.

Para a composição deste trabalho, recorremos à noção de expressão fixa, conforme esclarece Fulgêncio (2008, p. 101), "qualquer sequência de palavras que é memorizada pelos falantes da língua como um todo unitário, sendo igualmente recuperada da memória em bloco". São expressões que não devem ser interpretadas composicionalmente, ou seja, por meio da soma de seus elementos constituintes. A partir das definições apresentadas, deduzimos, simplificadamente, que os fraseologismos ou expressões fixas são uma combinação de palavras que apresentam 
Linha D’Água (Online), São Paulo, v. 32, n. 3, p. 117-136, set.-dez. 2019

características próprias, como certa estabilidade e rigidez estrutural e semântica, e que são memorizados em bloco pelo falante.

Para recorrermos mais uma vez à Cerqueira (2018), os falantes nativos de uma língua contam sobremaneira com unidades línguo-culturais disponíveis no seu sistema linguístico. A utilização dessas expressões línguo-culturais, em geral, fixas, é uma das formas de representar e categorizar o mundo, por meio de estruturas repletas de significação.

\section{Metodologia e constituição de corpus de culturemas}

A presente pesquisa sobre culturemas aproxima-se muito, em se tratando de procedimentos metodológicos, de pesquisas realizadas pelo Grupo de Investigação de Linguística Tipológica e Experimental (GILTE) da Universidade de Granada, que trabalha desde 1997 com temas relacionados ao léxico e às culturas das línguas modernas. Seguindo os passos do GILTE, selecionamos itens com acepções, exemplos e outras informações enciclopédicas para uma posterior formatação de um glossário línguo-cultural de termos regionais, a ser disponibilizado para a reedição crítica ou comentada da obra em tela.

No dicionário (independente) ou glossário línguo-cultural (anexado ao texto literário, como apêndice), base fundamental para um estudo de natureza mais interlinguística e intercultural, as relações entre cultura e linguagem são investigadas através do estudo de fraseologias, parêmias, palavras culturais, comparações proverbiais, piadas, alusões, trechos de músicas, discursos repetidos, clichês, slogans, etc. Aqui, daremos exemplos de expressões idiomáticas ou de locuções verbais com grau médio de idiomaticidade (metaforicidade).

Os processos metodológicos deste trabalho foram constituídos das seguintes etapas:

a) Leituras, releituras da edição antiga da obra: esta etapa consistiu na leitura da obra Capitães da Areia na sua edição mais antiga (1ª edição, de 1937). Após esse processo leitor, iniciamos o processo de buscas eletrônicas mais

MARTINS, V. P. S., GÉMES, M. T. Os idioculturemas em Capitĩes da Areia (1937), de Jorge Amado Todo conteúdo da Linha D'Água está sob Licença Creative Commons Attribution-NonCommercial 4.0 International License 
Linha D’Água (Online), São Paulo, v. 32, n. 3, p. 117-136, set.-dez. 2019

sistematizadas de culturemas em suas diversas manifestações formais, bem como contabilizando o número de ocorrências.

b) Revisão de literatura: realizamos nessa fase uma busca, no Google Acadêmico e em repositórios acadêmicos online de artigos, dissertações e teses, por pesquisas envolvendo culturemas em textos literários, com o objetivo de conhecer a sistemática das pesquisas já realizadas e suas temáticas

c) Levantamento de culturemas nos seus diversos âmbitos línguo-culturológicos: procuramos construir um inventário de culturemas, nos seus diversos âmbitos, na obra literária. Para esta etapa de trabalho, fizemos o recorte dos itens relacionados à cultura linguística, idiomatismos ou, como já mencionamos, anteriormente, idioculturemas.

d) Análise e refinamento dos culturemas: de posse da recolha de culturemas, seguimos para organização e análise desse material, iniciando uma discussão léxico-semântica.

A organização do levantamento dos culturemas percorreu os seguintes critérios:

Corpus: durante a constituição do corpus, todos os culturemas foram apresentados entre colchetes e hashtags, da seguinte forma: [\#culturema\#].

Contexto: cada um dos elementos do levantamento segue acompanhado do seu respectivo trecho em que aparece em Capitães da Areia (AMADO, 1937). Enriquecemos esta seção com informações etimológicas, datações e formas históricas (aqui, para deixarmos os culturemas, mais enxutos, procedemos com o apagamento dessas informações na seção). Graças a esse procedimento, poderemos, no futuro, propor datação e retrodatação para muitos verbetes do Grande Dicionário Houaiss (2009), nossa principal fonte de consulta quando da apresentação de acepções para os termos (verbetes e locuções) selecionados.

Referência: baseando-se na versão impressa da obra, incluímos, nas notas informativas de remissão sobre os culturemas, as indicações de página, como neste exemplo: (AMADO, 1937, 45).

MARTINS, V. P. S., GÉMES, M. T. Os idioculturemas em Capitães da Areia (1937), de Jorge Amado Todo conteúdo da Linha D'Água está sob Licença Creative Commons Attribution-NonCommercial 4.0 International License 
Linha D’Água (Online), São Paulo, v. 32, n. 3, p. 117-136, set.-dez. 2019

Informações enciclopédicas: nesta parte, couberam os comentários livres ou de caráter enciclopédico sobre os culturemas selecionados.

A classificação escolhida para nossa pesquisa foi baseada em Igareda (2011). Apesar de voltado para o campo da Tradução, elegemos o método de Igareda (2011) para embasar nosso corpus devido à sua amplitude e por ser direcionado para análise estilística do discurso literário, conforme Martins (2008), foco privilegiado neste trabalho.

A categorização de Igareda (2011, p. 19) é dividida gradativamente em três níveis, sendo: categorização temática, categorização por áreas e subcategorias. A autora divide o primeiro em sete classes: ecologia, história, estrutura social, instituições sociais, universo social, cultura material, aspectos linguísticos culturais e humor. Os demais níveis podem ser variados e receber novas nomenclaturas (por exemplo, moedaculturemas, para se referir a moedas), à medida que o pesquisador vai extraindo os culturemas do texto literário.

\section{Seleção de Idioculturemas}

Como afirmamos anteriormente, podemos conhecer a cultura da comunidade por meio de sua fraseologia, seja expressa na língua falada ou na língua escrita (PAMIES BERTRÁN, 2008; BOUGHABA, 2014; e MIRANDA MÁRQUEZ, 2014).

A língua literária, por excelência, pode ser considerada produto da cultura (Saussure, 2012, p. 54), sendo os culturemas os elementos culturais que melhor expressam o cotidiano, as tradições e os costumes de uma determinada comunidade. São os culturemas que, em geral, evocam uma realidade cultural, impregnada de símbolos e metáforas próprias de uma sociedade.

Os culturemas relacionados à identidade línguo-cultural mais frequentes em Capitães da Areia (1937), de Jorge Amado, permitem-nos adentrar no ambiente cultural vivenciado e construído pelo povo baiano. Alguns de seus culturemas, nesse âmbito, dizem muito da cultura baiana, do seu jeito idiossincrásico de ser, entre os quais citamos: [\#comentar para os botões da farda\#], [\#abrir no mundo\#], [\#acabar tutu\#] [\#acertar as contas\#], [\#agora é que vão ser elas\#], [\#andar

MARTINS, V. P. S., GÉMES, M. T. Os idioculturemas em Capitães da Areia (1937), de Jorge Amado Todo conteúdo da Linha D'Água está sob Licença Creative Commons Attribution-NonCommercial 4.0 International License 
Linha D’Água (Online), São Paulo, v. 32, n. 3, p. 117-136, set.-dez. 2019

ao azar\#], [\#andar ao léu\#], [\#bate o trinta e sete\#], [\#bater a caçuleta\#], [\#bater asa\#], [\#bater coisas\#],[\#bater coxa\#], [\#dar dois dedo de prosa comigo\#], [\#dobrar a língua\#], [\#estar com um peso da mãe\#], [\#fazer o amor (com)\#],[\#fazer o amor (completo) \#], [\#fazer os serviços\#],[\#fazer pelo sinal\#], [\#fechar a cancela\#], [\#fechar os olhos\#], [\#ficar com nó na garganta\#], [\#negro quando pinta, três vezes trinta\#], [\#pagar a pena\#], [\#pagar o bem com o bem\#], [\#pensar na morte da bezerra\#], [\#receber um presente de grego\#],[\#puxar ao\#], [\#puxar conversa (com)\#], [\#a sede é pior que uma cobra cascavel\#], [\#dar o fogo\#] [\#meter as mãos\#], [\#não ser pra teu bico\#], [\#tirar o cabaço (a)\#], [\#ficar em maus lençóis\#] e [\#tocar bronha\#]

Comentamos a seguir, a partir do conjunto de itens acima, alguns dos idioculturemas, em seus respectivos contextos, que, na eleição léxica de Jorge Amado, apresentaram maior grau de expressividade estilística em Capitães da Areia (AMADO, 1937).

\section{[\#COMENTAR PARA OS BOTÕES DA FARDA\#]}

"O guarda o espiava. Depois comentou para os botões da farda: - Bem dizem que estes poetas são doidos.” (CA, 1937, p. 185)

Trata-se de uma variação fraseológica de "falar com seus botões" com sentido de "falar consigo mesmo", levando o leitor a recuperar a forma fixa "aos seus botões ou com seus botões “, por metáfora, com sentido de "de si para consigo”.

\section{[\#ABRIR NO MUNDO\#]}

"Pedro Bala e João Grande abalaram pela ladeira da Praça. Barandão abriu no mundo também." (CA, 1937, p. 318)

Pelo contexto, equivalente a "cair no mundo", com acepção de "fugir, desaparecer".

\section{[\#ACABAR TÚTÚ\#]}

“- Tú não pode passar um dia sem bater coxas com esta bruaca, não é? Tú vae acabar tútú..” (CA, 1937, p. 92).

MARTINS, V. P. S., GÉMES, M. T. Os idioculturemas em Capitäes da Areia (1937), de Jorge Amado 
Linha D’Água (Online), São Paulo, v. 32, n. 3, p. 117-136, set.-dez. 2019

À primeira vista, pareceu-nos um cochilo editorial. Não se trataria de "acabar tútú", e sim, "acabar tatu", como variante da expressão "levar um tatu ou pegar um tatu" com acepção de "ser derrubado; cair", como nos sugere o contexto da expressão. Não encontramos um significado específico. Provavelmente é uma gíria da época, um jargão dos capitães da areia.

\section{[\#ACERTAR AS CONTAS\#]}

“- Então podem ir. Depois, tem que ser antes de duas horas, voltem aqui. Mas só quando a rua estiver deserta. Eu os esperarei. Acertaremos nossas contas então.” (CA, 1937, p. 76).

No sentido de "dar remuneração a; gratificar, recompensar", é bem transparente.

\section{[\#AGORA É QUE VÃO SER ELAS\#]}

“- Com certeza está com o homem. Agora é que vão ser elas.” (CA, 1937, 'p. 79). Mesmo que "agora é que são elas", com sentido de expressão usada para indicar que os problemas ou as dificuldades vão começar. São formas variantes e equivalentes em termos de acepção "agora é que são elas" ou "aí é que são elas”, "aí é que reside a dificuldade", "agora é que começam os problemas"; "aí é que bate o ponto”, aí é que a coisa fia fino”.

\section{[\#ANDAR AO AZAR\#]}

"Pedro Bala enquanto sobe a ladeira da Montanha vae pensando que não existe nada melhor no mundo que andar assim, ao azar, nas ruas da Bahia." (CA, 1937, p. 176).

Ao contexto dado, a acepção mais próxima seria a de "andar à sorte", isto é, "à sorte, ao acaso, a esmo; aleatoriamente, acidentalmente".

\section{[\#ANDAR AO LÉU\#]}

"Gostava de andar ao léu nas ruas da cidade, entrando nos jardins para fumar um cigarro sentado num banco, entrando nas igrejas para espiar a beleza do ouro velho, flanando pelas ruas calçadas de grandes pedras negras.” (CA, 1937, p. 94). 
Linha D’Água (Online), São Paulo, v. 32, n. 3, p. 117-136, set.-dez. 2019

Tem o mesmo sentido de "andar à toa, a esmo".

[\#BATE O TRINTA E SETE\#]

“- O Gringo andou ruim. Quasi bate o trinta e sete. Andou por pouco. Se não fosse Don'Aninha que deu beberagem a ele que botou ele em pé, tú não via mais ele. Tá mais magro que um espeto...” (CA, 1937, p. 168).

Com a acepção de "falecer, morrer; bater o trinta e um de roda, bater o trinta e um". Acreditamos que se trata de variação fraseológica ou uma "corruptela fraseológica" da expressão "bater o trinta e um" (hipótese da escrita da expressão distanciada de uma linguagem com maior prestígio social).

\section{[\#BATER A CAÇULETA\#]}

“- De que morreu, sua mãe? - Mesmo não sei. Deu uma coisa exquesita na pobre, uma febre de mau agouro, ela bateu a caçuleta em cinco dias. E me deixou só no mundo." (CA, 1937, p. 156).

Houaiss (2009) registra como acepção de "morrer; bater as botas" para a referida expressão.

\section{[\#BATER COXA\#]}

“- Tú não pode passar um dia sem bater coxas com esta bruaca, não é? Tú vae acabar tútú..” (CA, 1937, p. 92)

Atualmente, tem-se o substantivo "bate-coxa", forma tabuística de "relação sexual; cópula”.

\section{[\#DAR DOIS DEDO DE PROSA COMIGO\#]}

"- O "Loiro", que morreu na greve? Como não me lembro. Era um que toda tarde vinha dar dois dedo de prosa comigo. Gostava de tirar pilhéria."(CA, 1937, p.111) A locução fixa é "dois dedos de", com a ideia de "um tantinho, um pouquinho".

\section{[\#DOBRAR A LÍNGUA\#]}

“- Dobre a língua, filho da mãe.” (CA, 1937, p. 248).

Seria possível aqui uma metáfora mista: dobrar o joelho como sinal de respeito e dobrar a língua, falar de forma respeitosa. 
Linha D'Água (Online), São Paulo, v. 32, n. 3, p. 117-136, set.-dez. 2019

\section{[\#FAZER O AMOR COM ALGUÉM \#]}

"O Gato respondia aos sorrisos e seguia. Esperava que uma o chamasse e fizesse o amor com ele." (CA, 1937, p. 54)

Com o sentido da obra, atualmente, utilizamos a expressão, sem o artigo "o", "fazer amor" com sentido informal de "manter relações sexuais; copular".

\section{[\#FECHAR A CANCELA\#]}

"Já fechei a cancela, Boa Vida. Passei da idade. Pergunta a este. — apontava João de Adão. - Vi quando ele, quasi menino assim como tú, fez a primeira greve aqui nas doca. Naquele tempo ninguém sabia que diabo era greve. Tú te lembra, compadre?” (CA, 1937, p. 110).

Equivalente hoje a "não ter mais relações sexuais".

\section{[\#FICAR COM NÓ NA GARGANTA\#]}

"Olhou o desenho semi-apagado, seguio seu caminho ainda com as mãos nos rins. Ia quasi sem pensar, com um nó na garganta.” (CA, 1937, p. 129)

Houaiss (2009) data a locução de 1551, cuja acepção é "aperto na garganta causado por uma emoção forte”.

\section{[\#NEGRO QUANDO PINTA, TRÊS VEZES TRINTA\#]}

"Pedro Bala falou: - Negro quando pinta, três vezes trinta." (CA, 1937, p. 110). A expressão "negro quando pinta três vezes trinta" era uma expressão utilizada para dizer que os negros não aparentavam a idade que tinham. Negro quando apresenta a idade (pinta), já tem muito mais do que se imagina (três vezes trinta).

\section{[\#PENSAR NA MORTE DA BEZERRA\#]}

“-Tá pensando na morte da bezerra, seu mano?" (CA, 1997, p. 113).

No contexto, há um interessante caso de uso de "seu mano" como interlocutório pessoal. Trata-se de uma fraseologia cujo sentido idiomático é "estar distraído ou absorto consigo próprio; estar pensativo, não estar atento ao que se passa em torno" 
Linha D'Água (Online), São Paulo, v. 32, n. 3, p. 117-136, set.-dez. 2019

\section{[\#SABER O SEU A. B. C.\#]}

“- Até parece Rosa Palmeirão. Nunca houvera mulher tão valente como Rosa Palmeirão. Dera em seis soldados de uma vez. Todo marítimo sabe o seu A. B. C. no cais da Bahia. Por isso Dora gosta da comparação e sorri: - Obrigado, mano." (CA, 1937, p. 251).

A acepção figurativa mais adequada ao contexto é a mesma de $b \hat{e}-a-b a ́$, isto é, "história relatada; narrativa”.

\section{[\#TÁ COMO URUBU EM CIMA DE CARNIÇA\#]}

“-Tá tudo como urubu em cima de carniça.” (CA, 1937, p. 226).

Uma variação fraseológica de "tá mais alegre do que urubu na carniça”, com a acepção figurativa mais aproximada de "abutre”, isto é, "pessoa que espera ou deseja a morte ou o desaparecimento de outrem de modo a obter bens ou vantagens".

\section{[\#NÃO SER PRA TEU BICO\#]}

"A negra atirou o chinelo, Boa Vida desviou o corpo:- Se eu tivesse uma filha não era pra teu bico, malandro.” (CA, 1937, p. 114).

Trata-se de fraseologia com sentido idiomático de "não estar de acordo com as possibilidades de (alguém)".

\section{[\#TIRAR O CABAÇO (A)\#]}

“- Quem tirou teu cabaço?- Ora, me deixe ... - respondeu o pederasta rindo." (CA, 1937, p. 136).

Com acepção de desvirginar, descabaçar (especialmente, mulher), mas o contexto refere-se a desvirginamento do pederasta "Mariasinha".

\section{[\#FICAR EM MAUS LENÇÓIS\#]}

"Almiro foi mesmo levado para o lazareto e o padre ficou em maus lençóes pois o medico (que se dizia livre-pensador, mas em verdade era espirita) denunciou o padre também como encobridor do caso." (CA, 1937, p. 196).

Com pelo menos duas acepções adequadas ao contexto: (i) "em situação crítica, difícil, arriscada”; e (ii) "em posição indefensável perante seus acusadores”. 
Linha D'Água (Online), São Paulo, v. 32, n. 3, p. 117-136, set.-dez. 2019

\section{[\#TOCAR BRONHA\#]}

"- Mesmo esse couro - disse o Gato - não me tenta. Nem pra me tocar bronha." (CA, 1937, p. 58).

Automasturbação, isto é, masturbação praticada em si próprio

\section{Considerações finais}

No decorrer deste trabalho se evidenciou, de forma bastante explícita, o quanto o conhecimento de culturemas é importante para uma recepção adequada de Capitães da Areia (AMADO, 1937), e, por outro lado, da diversidade linguística, tanto no sentido sincrônico, como diacrônico. O recorte cultural e linguístico que o romance de Amado nos traz representa falas e expressões bastante específicas as da cultura urbana e popular baiana da entre-guerras - que se constituem, desta forma, como representação da diversidade cultural brasileira ou, como diria Darcy Ribeiro, de uma das muitas ilhas Brasis. Enquanto alguns destes culturemas marcam e distinguem, portanto, a cultura e, em última instância, a identidade baiana dos anos 30, outros demonstram, pela sua transparência e emprego em outras ilhas Brasis, uma rica relação de interfecundação linguística entre diferentes regiões do Brasil e, portanto, expressam uma identidade linguística brasileira.

Sabemos que este trabalho só pode ser um início, tanto em relação a uma práxis leitora, seja isto no ensino médio ou na aprendizagem do português brasileiro como segunda língua, quanto na pesquisa de culturemas em busca de uma descrição das identidades linguísticas e culturais do Brasil. É evidente que textos literários são, em muitos aspectos, fontes muito proveitosas para essas atividades. Representando, por necessidade, experiência humana, estão enraizados nos tempos e espaços culturais-linguísticos da sua gênese, enquanto, ao mesmo tempo, ultrapassam essas em direção ao universal.

A pesquisa, no futuro, deverá aprofundar-se ainda em relação às origens, à motivação e à difusão desses culturemas, tanto no sentido diacrônico, como em sentidos sincrônicos, como a questão de regiões, grupos sociais ou profissões. O quanto isto pode constituir-se como desafio se demonstrou, claramente, no

MARTINS, V. P. S., GÉMES, M. T. Os idioculturemas em Capitães da Areia (1937), de Jorge Amado Todo conteúdo da Linha D'Água está sob Licença Creative Commons Attribution-NonCommercial 4.0 International License 
Linha D’Água (Online), São Paulo, v. 32, n. 3, p. 117-136, set.-dez. 2019

culturema [\#acabar tútú\#]. No entanto, entendemos que este trabalho se constitui como um primeiro passo da exploração cultural-linguístico ou línguo-culturológica dessa obra significativa e que pode servir de modelo para pesquisas sobre outras obras.

\section{Referências}

AMADO, J. Capitães da areia. Rio de Janeiro: J. Olympio, 1937. Disponível em https://digital. bbm.usp.br/handle/bbm/6845. Acesso em 17/06/2019.

BOUGHABA, M. Las unidades fraseológicas y la traducción de culturemas entre elespañol y el árabe. Paremia, 23: 2014, p. 209-216. Disponível em https:/cvc.cervantes.es/lengua/paremia/ pdf/023/019_boughaba.pdf. Acesso em 12/07/2018

CARDOSO, E. de A. O léxico no discurso literário: a criatividade lexical na poesia moderna e contemporânea. São Paulo: EDUSP, 2018.

. Escolhas lexicais: a caracterização de personagens femininas no discurso literário. Linha D’Água, v. 26, n. 1, p. 15-28, 27 jun. 2013. Disponível em http://www.revistas.usp.br/linhadagua/ article/view/55324. Acesso em 10/05//2019

CASARES, J. Introducción a la lexicografia moderna. Madrid, CSIC, 1969.

CERQUEIRA, G. C. Os fraseoculturemas em sombras de reis barbudos, de José J. Veiga. 2018. 64 f. Monografia (Graduação em Letras) - Centro de Filosofia, Educação e Letras da Universidade Estadual Vale do Acaraú (UVA) - Sobral, UVA, 2018.

CORPAS-PASTOR, G. Manual de fraseologia española. Madrid: Gredos, 1996.

ELIAS, N.; SCOTSON, J. L. Os estabelecidos e os outsiders: sociologia das relações de poder a partir de uma pequena comunidade. Rio de Janeiro: Jorge Zahar, 2000.

GIRACCA, M. N. Os culturemas presentes nos folhetos turisticos da região sul do Brasil: as técnicas utilizadas pelos tradutores. Dissertação (mestrado) - Universidade Federal de Santa Catarina,

MARTINS, V. P. S., GÉMES, M. T. Os idioculturemas em Capitães da Areia (1937), de Jorge Amado Todo conteúdo da Linha D'Água está sob Licença Creative Commons Attribution-NonCommercial 4.0 International License 
Linha D’Água (Online), São Paulo, v. 32, n. 3, p. 117-136, set.-dez. 2019

Centro de Comunicação e Expressão, Programa de Pós-graduação em Estudos da Tradução, Florianópolis, 2013.

HOUAISS, A.; VILLAR, M. de S.; FRANCO, F. M. de M. Dicionário Houaiss da língua portuguesa. Rio de Janeiro: Objetiva, 2009. [CD-ROM]

IGAREDA, P. Categorización temática del análisis cultural: una propuesta para la traducción. Íkala, Revista de Lenguaje y Cultura, Vol. 16, No. 27 (enero - abril de 2011), p. 11-31 Disponível em: http://www.scielo.org.co/pdf/ikala/v16n27/v16n27a2.pdf Acesso em 02/02/2018.

LEGROSKIL, M. C. Graduação de composicionalidade: um estudo de caso com expressões idiomáticas e ditados populares. Estudos Linguísticos, São Paulo, 41 (1): p. 340-354, jan-abr 2012. Disponível em https://revistas.gel.org.br/estudos-linguisticos/article/view/1237/790. Acesso em 28/06/2019.

LUQUE NADAL, L. Los culturemas: ¿unidades linguísticas, ideológicas o culturales?,Language Design, 11, 2009: p. 93-120. Disponível em http://elies.rediris.es/Language_Design/LD11/ LD11-05-Lucia.pdf. Acesso em 15/05/2019

Princípio de culturología y fraselogíaespañolas. Frankfurt AmMain: Peter Lang, 2012.

MARTINS, N. S. Introdução à estilística: a expressividade na língua portuguesa. São Paulo: EDUSP, 2008.

MARTINS, V. de P. da S. Estratégias de compreensão de expressões idiomáticas por não nativos do português Brasileiro. Tese (doutorado) - Universidade Federal do Ceará, Centro de Humanidades, Departamento de Letras Vernáculas, Programa de Pós-Graduação em Linguística, Fortaleza, 2013. Disponível em: http://www.repositorio.ufc.br/handle/riufc/8233. Acesso em 19/02/18.

MATTIOLI, V. Identificación y clasificación de culturemas y procedimientostraductoresenelarchivo de textos literarioslit_enit_es: unestudio de corpus. Máster eninvestigaciónentraducción e interpretación. Castelló de la Plana: UniversitatJaume I de Castelló, Traducción y ComunicaciónDepartment, 2014.

MILANI, S. E. Humboldt e o idealismo da época. Linha d’Agua, v. 21, p. 24-33, 2008. Disponível em http://www.revistas.usp.br/linhadagua/article/view/37313/40033. Acesso em 14/06/2018.

MARTINS, V. P. S., GÉMES, M. T. Os idioculturemas em Capitães da Areia (1937), de Jorge Amado Todo conteúdo da Linha D'Água está sob Licença Creative Commons Attribution-NonCommercial 4.0 International License 
Linha D’Água (Online), São Paulo, v. 32, n. 3, p. 117-136, set.-dez. 2019

MIRANDA MÁRQUEZ, G. El vínculo inseparable entre lengua y cultura. Casos de elementos conrelevancia simbólica enlenguas asiáticas. Language Design, 16, 2014, p. 41-62.

MOÇO, M. G. D. M. O texto literário como veículo intercultural no ensinolaprendizagem da língua portuguesa. Lisboa, 2015. Disponível em http://www.revistas.usp.br/viaatlantica/article/ view/98622. Acesso em 03/07/2018.

MOLINA MARTÍNEZ, L. Análisisdescriptivo de latraducción de losculturemas árabe-español. Tese (doutorado) - UniversitatAutònoma de Barcelona - Departament de Traducció i d'Interpretació .Bellaterra: UniversitatAutònoma de Barcelona, 2001

OYARZABAL, M. V. O carnaval e suas traduções: os desafios da ressignificação dos culturemas. Dissertação (mestrado) - Universidade Federal de Santa Catarina, Centro de Comunicação e Expressão, Programa de Pós-Graduação em Estudos da Tradução, Florianópolis, 2013.

PAMIES BERTRÁN, A. Productividad fraseológica y competencia metafórica (inter)cultural. Paremia 17: p. 41-58, 2008.

POTTIER, B. Linguística geral: teoria e descrição. Rio de Janeiro: Presença: Universidade Santa Úrsula, 1978. p. 268- 276.

SANTIAGO, J. P. O culturemaamélia: uma unidade linguística, ideológica e cultural do português brasileiro. Dissertação (mestrado) - Universidade Federal do Ceará, Centro de Humanidades, Departamento de Letras Vernáculas, Programa de Pós-Graduação em Linguística, Fortaleza, 2014. Disponível em http://www.repositorio.ufc.br/handle/riufc/14868. Acesso em 13/08/2018.

SAUSSURE, F. de. Curso de linguística geral. São Paulo: Cultrix, 2012.

TANOS ROBEIN, L. Relativismo Linguístico: críticas y perspectiva actual de lateoría. In VI Simposio Internacional: Representaciónen la Ciencia y el Arte, Córdoba, Argentina, 2013, p. 1-10.

ZULUAGA, A. Introducción al estudio de lasexpresiones fjas. Frankfurt amMaim: Peter D. Lang, 1980.

Recebido: 30/7/2019.

Aprovado: 11/11/2019.

MARTINS, V. P. S., GÉMES, M. T. Os idioculturemas em Capitĩes da Areia (1937), de Jorge Amado Todo conteúdo da Linha D'Água está sob Licença Creative Commons Attribution-NonCommercial 4.0 International License 